A continuidade e a morte: esfacelamento da individuação em Georges Bataille -Bárbara de Barros AnaLógos, Rio de Janeiro, v. 1, 2016, p. 90-96

\title{
A CONTINUIDADE E A MORTE: ESFACELAMENTO DA INDIVIDUAÇÃO EM GEORGES BATAILLE
}

\author{
Bárbara de Barros \\ Mestranda em Filosofia pela UFF
}

\begin{abstract}
Resumo: Este artigo tem como objetivo apresentar a relação entre as ideias de continuidade e morte utilizados no livro O Erotismo de Georges Bataille. Para isso, situaremos a discussão em sua obra, precisamente na formulação ontológica do excesso e na dinâmica existente entre as noções de interdito e transgressão. De tal maneira, poderemos entender a disrupção do sujeito em contato com o erotismo e a morte.

Palavras-chave: Bataille, Continuidade, Morte, Erotismo.
\end{abstract}

Ao longo da obra de Georges Bataille podemos perceber a repetição de determinadas temáticas que aparecem persistentemente nos mais diversos conceitos. Uma delas se delineia como o problema da individuação: como o ser individual pode se separar do ser da totalidade, ou, de outro modo, como a descontinuidade consegue se diferenciar da continuidade? Para podermos pensar essas questões, é necessário que situemos essa querela em sua obra, e como ela se relaciona com os outros conceitos por ele utilizados.

Neste artigo nos ateremos aos conceitos de continuidade e de morte para podermos expressar essa disrupção no sujeito em Bataille. Ambos os conceitos são exaustivamente utilizados em seu livro mais conhecido, O Erotismo, e são ordenados a partir da perspectiva ontológica que Bataille desenvolve a partir do excesso.

Para entendermos o que seria essa perspectiva ontológica podemos nos ater a duas aterradoras frases de Bataille. A primeira é a de que "o ser é 
A continuidade e a morte: esfacelamento da individuação em Georges Bataille -Bárbara de Barros AnaLógos, Rio de Janeiro, v. 1, 2016, p. 90-96

também o excesso do ser, elevação ao impossível. " Ao afirmar uma asserção como esta, Bataille visa nos demonstrar o que ele entenderá como uma espécie de princípio ontológico, no caso, o excesso. Para ele, o excesso seria a base de tudo que é, o que decorre na insuficiência da linguagem que nunca pode abarcar o ser em sua totalidade, visto que o ser escapa às explicações racionais discursivas da filosofia.

Compreendendo que o ser é excesso do ser, Bataille coloca que tudo que é, escapa, transborda a qualquer estrutura estanque moldada por nossos olhos antropomórficos. A partir da crítica ao antropocentrismo que reina na ciência e na filosofia - que começa com o conceito de informe e continua ao longo de seus escritos -, Bataille estrutura a noção de economia geral, na qual ele tece uma afiada crítica à noção clássica de utilidade ao colocar a perda e o gasto como centrais na economia, pois "não é a necessidade mas seu contrário, o 'luxo' que coloca para a matéria viva e para o homem seus problemas fundamentais."2

Para Bataille, o universo abarca uma quantidade de energia excedente e, no âmbito global, dispomos de mais energia que o necessário para a nossa existência, o que incorre numa abundância que deve ser gasta improdutivamente. Ele entende que esse excesso tem uma dimensão cósmica, na qual o excesso que nos engendra é produto dos raios solares que tem um efeito fecundo sobre a vida. Assim,

o organismo vivo, na situação determinada pelos jogos da energia na superfície do globo, recebe em princípio mais energia do que é necessário para a manutenção da vida: a energia (a riqueza) excedente pode ser utilizada para 0 crescimento de um sistema (de um organismo, por exemplo); se o sistema não pode mais crescer, ou se o excedente não pode ser inteiramente absorvido em seu crescimento, é preciso necessariamente perdê-lo sem lucro, despendê-lo, de boa vontade ou não, gloriosamente ou de modo catastrófico. ${ }^{3}$

\footnotetext{
${ }^{1}$ BATAILLE, G. O erotismo. p. 201

${ }^{2}$ BATAILLE, G. A parte maldita. p. 39

${ }^{3}$ BATAILLE, G. A parte maldita. p. 45 
A continuidade e a morte: esfacelamento da individuação em Georges Bataille -Bárbara de Barros AnaLógos, Rio de Janeiro, v. 1, 2016, p. 90-96

Desta forma, o excesso é subjacente a tudo que existe na Terra e é responsável por toda geração e destruição, o que qualifica essa energia como abundante e - sobretudo - violenta. Essa violência decorrente da devastação de seres individuais e da criação de novos seres a partir da matéria orgânica, que sempre se renova, possibilita a percepção entre excesso e natureza.

Por sua característica inerentemente excessiva, a natureza corresponde a um tipo de ameaça ao sujeito, pois não respeita essa divisão da descontinuidade do indivíduo humano e coloca-o em risco de dissolução a todo momento a partir de sua aparição enquanto morte - incumbida do ciclo criação/destruição - , figura da organicidade violenta e aterradora que movimenta o informe.

Para a relação entre natureza e excesso tornar-se mais evidente, podemos partir para o modo como Bataille entende a dinâmica do corpo social. Isso pode ser feito abordando como o indivíduo tenta se proteger da virulência da natureza de modo que possa persistir em sua descontinuidade, preservando a espécie e mantendo a existência da sociedade.

Há a instituição de interditos pelo homem como forma de prevenção ao excesso da natureza, e esses interditos seriam uma espécie de barreira que os resguarda do excesso. Os interditos marcam a separação entre o homem e o animal, e inscrevem o ser humano no que Bataille chama de "mundo profano", que é o mundo das coisas, do trabalho.

Os três interditos primordiais respondem ao âmbito da morte, da sexualidade livre e do trabalho. Eles atendem a uma necessidade do corpo social de manter-se afastado do excesso que insurge em atividades como: o contato erótico desmedido, o assassinato desenfreado e a ociosidade plena, já que todas essas possibilidades direcionam a um esgotamento da sociedade, ocaso da produção e manutenção da vida social.

Todavia, mesmo com a postulação dos interditos e, consequentemente, a instauração do "mundo profano", não podemos perder de vista que o ser é excesso do ser. Logo, o excesso que subjaz a existência habita também o cerne 
A continuidade e a morte: esfacelamento da individuação em Georges Bataille -Bárbara de Barros AnaLógos, Rio de Janeiro, v. 1, 2016, p. 90-96

do ser descontínuo. Temos aí uma contradição: o ser descontínuo quer perdurar na existência, resguardando-se do excesso com os interditos; contudo, é excesso dele mesmo e anseia pela experiência desse excesso, dessa continuidade violenta.

Encontramos aí o segundo termo da dinâmica de opostos: a transgressão. Ela é responsável pela abertura ao "mundo sagrado", que é caracterizado como o reino da soberania, da festa, e que escapa ao império da finalidade e da racionalidade instrumental que são características do mundo profano do trabalho. A transgressão é a entrada privilegiada para o mundo sagrado, que é aquilo que permanece além dos limites do campo do trabalho e é o contrário deste, visto que é a face da natureza que se mostra irredutível a qualquer dominação proveniente do trabalho.

A transgressão possibilita ao indivíduo descontínuo um momento de contato com a continuidade, em que ele desfruta de um flerte, um instante imerso no excesso, em que suas estruturas subjetivas pautadas na racionalidade são dissolvidas e o indivíduo tem uma "experiência interior", que é justamente o acesso à continuidade a partir da fissura ontológica que é característica dos seres descontínuos.

Dois exemplos desse acesso à continuidade fornecidos por Bataille são a atividade erótica e o sacrifício. No sacrifício, a participação da comunidade no processo de imolação do ser descontínuo proporciona um sentimento de continuidade, no qual a violência irrompe a partir da morte do sacrificado e fornece aos participantes um contato com o excesso da continuidade. Porém, esse contato ocorre de maneira que o ser descontínuo de cada participante seja mantido, visto que é o ser imolado que trava contato pleno com a continuidade através da morte.

O sacrifício é visto como uma atividade que vai contra a produção, pois o principal do sacrifício é a comunicação, a transição do mundo das coisas para o sagrado; o que é importante não é o jorrar do sangue da vítima, mas a passagem do reino da duração para o da consumação inútil. "O sacrifício é a 
A continuidade e a morte: esfacelamento da individuação em Georges Bataille -Bárbara de Barros AnaLógos, Rio de Janeiro, v. 1, 2016, p. 90-96

antítese da produção, esta feita em vista do futuro, ele é a consumação que não tem por interesse nada além do instante mesmo. ${ }^{4 \prime \prime}$

Por sua vez o erotismo, com o êxtase do orgasmo - a petite mort também nos propicia a experiência da continuidade. No ápice da convulsão sexual em que nossa descontinuidade colapsa na fusão com o outro, nos avizinhamos da morte por conta do excesso dessa movimentação. Bataille esclarece isso ao dizer que:

toda a operação do erotismo tem por fim atingir o ser no mais íntimo, no ponto em que o coração desfalece. A passagem do estado normal ao de desejo erótico supõe em nós a dissolução relativa do ser constituído na ordem descontínua. (BATAILLE, 2013, p. 41)

Essa asserção demonstra a operação destrutiva que ocorre na atividade erótica em relação à estrutura do ser fechado, violentando a unidade fixa que exprime a particularidade do ser. Temos, então, a relação entre a dissolução realizada pelo erotismo e o fascínio pela morte, signo máximo desta dissolução.

Retornando ao início do texto, chegamos à segunda frase aterradora de Bataille, no caso a afirmação de que: "do erotismo, é possível dizer que é a aprovação da vida até na morte. ${ }^{51}$ Essa sentença é capaz de expressar nitidamente a dinâmica entre a vida e a morte, balizadas pelo erotismo e pela continuidade.

A asserção de Bataille deixa claro como o indivíduo imerge na indistinção da continuidade durante o movimento erótico, a partir de sua fusão com outro ser, tendo ambos suas individualidades diluídas. Esta desagregação das estruturas subjetivas enseja uma aproximação da morte, a partir dessa imersão na continuidade, em que nos abrimos ao excesso.

Como já mencionamos anteriormente, enquanto o indivíduo descontínuo consegue resistir ao paroxismo do orgasmo e ao excesso da petite mort, a morte já não permite tal resistência, é impiedosa e não possibilita a subsistência do

\footnotetext{
${ }^{4}$ BATAILlE, G. Théorie de la Religion, p. 66

${ }^{5}$ BATAILLE, G. O erotismo. p. 35
} 
A continuidade e a morte: esfacelamento da individuação em Georges Bataille -Bárbara de Barros AnaLógos, Rio de Janeiro, v. 1, 2016, p. 90-96

indivíduo ao excesso que assola. Podemos perceber essa relação fraterna com a morte no jogo do erotismo, de fusão e abertura ao ser, de afrouxamento das estruturas subjetivas que propicia o contato com a continuidade:

há na passagem da atitude normal ao desejo uma fascinação fundamental pela morte. $O$ que está em jogo no erotismo é sempre uma dissolução das formas constituídas. Repito-o: dessas formas de vida social, regular, que fundam a ordem descontínua das individualidades definidas que somos. ${ }^{6}$

Não só as formas subjetivas são abaladas no processo erótico, mas também toda a ordem descontínua, que pauta a estreiteza das regulações sociais. A transgressão inerente ao erotismo suscita a manifestação do excesso tanto nos indivíduos como no corpo social e traz o perigo da morte para a superfície.

Há um excesso horrível do movimento que nos anima: o excesso ilumina o sentido do movimento. Mas, para nós, trata-se apenas de um sinal pavoroso, incessantemente nos lembrando que a morte, ruptura dessa descontinuidade individual a que a angústia nos prende, se propõe a nós como uma verdade mais eminente do que a vida. ${ }^{7}$

Ao entendermos que a morte exerce um papel dentro do erotismo, podemos assimilar o modo de sua operação, como o êxtase que é atingido a partir da fusão violenta dos corpos com o gozo, fazendo parte das experiências soberanas do mundo sagrado que não se submetem à finalidade alguma. $O$ erotismo introduz em nós um desequilíbrio, que nos faz colocar nosso ser em jogo:

o erotismo, já o disse, é a meus olhos o desequilíbrio em que o próprio ser se coloca em questão, conscientemente. Em certo sentido, o ser se perde objetivamente, mas então

\footnotetext{
${ }^{6}$ BATAILLE, G. O erotismo. p. 42

${ }^{7}$ BATAILLE, G. O erotismo. p. 42
} 
A continuidade e a morte: esfacelamento da individuação em Georges Bataille -Bárbara de Barros AnaLógos, Rio de Janeiro, v. 1, 2016, p. 90-96

o sujeito se identifica com o objeto que se perde. Se for preciso, posso dizer, no erotismo: EU me perco. ${ }^{8}$

Esse movimento vertiginoso que decorre do erotismo se deve ao contato do ser individual com a continuidade. Ao se jogarem no fluxo de comunicação com outro ser - que se abre na reação de arrebatamento que ocorre no êxtase , as descontinuidades são parcialmente dissolvidas e entram em contato com a violência do excesso.

O erotismo é pautado na transgressão tanto do interdito da sexualidade como na transgressão dos próprios limites de nossa constituição subjetiva, escapando da subserviência homogênea frente à razão.

Em suma, constatamos que a partir da ontologia do excesso presente na obra de Bataille é possível traçar uma relação entre a continuidade, o erotismo e a morte, na qual o indivíduo descontínuo é desestruturado e busca a totalidade do excesso - que precede e sucede sua individuação - , o que mostra que a descontinuidade procura seu próprio desmantelamento no flerte com a continuidade, onde nenhuma individualidade persiste.

\section{Bibliografia:}

BATAILlE, G. A parte maldita. Tradução: Júlio Castañon Guimarães. Belo Horizonte: Autêntica, 2013.

G. O erotismo. Tradução: Fernando Scheibe. Belo Horizonte: Autêntica, 2013.

G. Théorie de la religion. Paris: Gallimard, 1973.

\footnotetext{
${ }^{8}$ BATAILLE, G. O erotismo. p. 55
} 